Int. J. Electrochem. Sci., 15 (2020) $8901-8912$

\title{
Simple and Rapid Determination of Tartrazine Using Poly(l- arginine)/Electrochemically Reduced Graphene Oxide Modified Glassy Carbon Electrode
}

\author{
Peilong Wang ${ }^{1,2}, \mathrm{Xu} \mathrm{Liu}^{l}$, Qingqing $\mathrm{Hu}^{l}$, Hui Gao ${ }^{1,{ }^{*}}$ and Wei Ma ${ }^{1, *}$ \\ ${ }^{1}$ School of Chemistry and Materials Science, Huaibei Normal University, Huaibei, Anhui 235000, \\ China \\ ${ }^{2}$ Information School, Huaibei Normal University, Huaibei, Anhui 235000, China \\ *E-mail: gaohuichem@chnu.edu.cn
}

doi: $10.20964 / 2020.09 .83$

Received: 2 May 2020 / Accepted: 11 July 2020 / Published: 10 August 2020

\begin{abstract}
A simple and rapid electrochemical method based on a poly(L-arginine)-electrochemically reduced graphene oxide-modified glassy carbon electrode fabricated by cyclic voltammetry has been developed for the determination of tartrazine. Compared with the bare glassy carbon electrode, the modified electrode achieved a well-defined and enhanced oxidation peak due to the increased conductivity and electrochemical active surface area. The bare glassy carbon electrode and the modified electrode were characterized by scanning electron microscopy and electrochemical impedance spectroscopy. The electrocatalytic oxidation behaviors of tartrazine on the modified electrode were investigated using cyclic voltammetry and differential pulse voltammetry. The voltammetric peak current of tartrazine exhibits good linearity in the range of $1.00 \times 10^{-6}-2.50 \times 10^{-4} \mathrm{~mol} \mathrm{~L}^{-1}$ under the optimal differential pulse voltammetry conditions, with a detection limit of $2.5 \times 10^{-7} \mathrm{~mol} \mathrm{~L}^{-1}$ (at an $\mathrm{S} / \mathrm{N}$ of 3 ). This proposed method has also been applied for quantitative analysis of tartrazine in some carbonated beverage and fruit juice samples, with satisfactory results.
\end{abstract}

Keywords: L-arginine, reduced graphene, tartrazine, modified electrode Synopsis (graphical abstract):

\section{$\underline{\text { FULL TEXT }}$}

(C) 2020 The Authors. Published by ESG (www.electrochemsci.org). This article is an open access article distributed under the terms and conditions of the Creative Commons Attribution license (http://creativecommons.org/licenses/by/4.0/). 